\title{
Computational analysis of 'Dose/Collision Kerma' relationship and lateral boundary in Stereotatic circular fields using EGSnrc.
}

\author{
Reginaldo G. Leão Jr. ${ }^{1,2}$, Rômulo V. de Sousa ${ }^{4}$, Arno H. de Oliveira ${ }^{1}$, Hugo L. L. Silva ${ }^{5}$, \\ Arnaldo P. Mourão ${ }^{1,3}$ \\ 1 Department of Nuclear Engineering/Federal University of Minas Gerais, Belo Horizonte, Brazil \\ ${ }^{2}$ Center for Research in Physics and Engineering Applied to Health/ Federal Institute of Minas Gerais, Arcos, \\ Brazil \\ ${ }^{3}$ Biomedical Engineering Center/Federal Center for Technological Education of Minas Gerais, Belo \\ Horizonte, Brazil \\ ${ }^{4}$ São João de Deus Hospital, Divinópolis, Brazil \\ ${ }^{5}$ Santa Casa Hospital, Belo Horizonte, Brazil
}

\begin{abstract}
Resumo
Objetivos: Este trabalho teve como objetivo principal a obtenção de dados de pequenos campos de raios $X$ que evidenciassem as hipóteses apontadas como dificultadoras para a dosimetria destes. Foi realizada a verificação da compatibilidade entre o limite do campo dosimétrico com o campo geométrico e a verificação da relação kerma-dose segundo o esperado para campos convencionais. Materiais e Métodos: Simulações computacionais de campos menores que $5 \times 5 \mathrm{~cm}^{2}$ foram realizadas utilizando o método de Monte Carlo por meio da aplicação egs_chamber, esta derivada do código de transporte de radiação EGSnrc. Como fontes de partículas, foram utilizados phase space files de um modelo de cabeçote do acelerador linear CLINAC 2100 acoplado a cones de Radiocirurgia Estereotáxica. Resultados: As simulações sugeriram a existência de um patamar, próximo de 8\%, nas discrepâncias entre o FWHM da Dose e o diâmetro nominal do campo, indicando um decréscimo destes valores para campos de diâmetros menores que $12 \mathrm{~mm}$ e maiores que 36 $\mathrm{mm}$. Simultaneamente, as discrepâncias dose-kerma em profundidade atingiram valores superiores a $14 \%$ no caso onde o fenômeno foi mais significativo. Conclusão: Os dados da relação kerma-dose mostraram que, de fato, o comportamento dos pequenos campos destoa daquele esperado para campos convencionais, e que as convenções dosimétricas tradicionais não se aplicam a tais campos, sendo necessária uma abordagem especializada para as técnicas que os empregam. Além disto, a existência do já referido patamar de discrepâncias, juntamente com a diminuição destas em campos de diâmetro menor que $15 \mathrm{~mm}$, constituem um achado notável.
\end{abstract}

Palavras-chave: Pequenos Campos, Dosimetria, Monte Carlo, EGSnrc

\begin{abstract}
Objectives: This work aimed to obtain data from small fields of $X$-rays that evidence of the hypotheses cited as cause of difficulties for the dosimetry of these. For this purpose, the verification of compatibility between the dosimetric boundary of field and the geometric size of field, was performed. Also, the verification of kerma dose according to the expected relationship for conventional fields was made. Materials and Methods: Computer simulations of smaller fields $5 \times 5 \mathrm{~cm}^{2}$ were performed, using the Monte Carlo method by egs_chamber application, this derived from EGSnrc radiation transport code. As particulate sources were used phase space files of a Clinac 2100 head model coupled to cones Stereotactic Radiosurgery. Results: The simulations suggested the existence of a plateau in discrepancies between the dose FWHM and the nominal diameter of the field close to $8 \%$. These simulations also indicated a decrease of these values for fields with diameters smaller than $12 \mathrm{~mm}$ and larger than $36 \mathrm{~mm}$. Simultaneously, the dose kerma differences in depth reached values higher than $14 \%$ in the case where the phenomenon is more significant. Conclusion: The data showed that in fact the behavior of small fields clashes with that expected for conventional fields, and that the traditional dosimetric conventions do not apply to such fields requiring a specialized approach to the techniques that employ them. Furthermore, the existence of the aforementioned plateau of discrepancies, along with the decrease thereof in less than $15 \mathrm{~mm}$ diameter fields constitute a remarkable finding.
\end{abstract}

Keywords: Small Fields, Dosimetry, Monte Carlo, EGSnrc 


\section{Introduction}

The evolution of techniques and protocols available for therapeutic methods using ionizing radiation are proving very promising. However, they also have brought new challenges mainly due to the use of different physical conditions of those already well established in conventional radiotherapy.

In this scope is important to devote special attention to the techniques that make use of small fields of $X$ ray or even dynamic fields to achieve their goals and confer advantages over their predecessors. The radiosurgery (RS) and of Intensity Modulated Radiotherapy (IMRT) techniques stand out for being widespread in the world, but not yet fully consolidated dosimetric point of view.

Radiosurgery is a technique that uses a combination of static fields noncoplanar with millimetric dimensions to provide a highly concentrated dose distribution and high precision. Its main indications are neoplastic or non-neoplastic treatments when surgical access is contraindicated. The prescribed dose can be a single fraction or up to five Hypofractionated session [1,2].

Currently, these small fields are produced with the aid of collimation tool in conventional linear accelerators by means of cones and micro multileaf systems (MMLC), or by devices dedicated to this purpose, as Cyberknife and Gamma Knife.

Intensity-Modulated Radiation Therapy, although use larger fields that RS, it uses beam field fractions in which physical conditions similar to radiosurgery are caused [3]. Therefore, being subject to similar dosimetric difficulties to commonly encountered in radiosurgery.

Various regulatory agencies and research groups have proposed quality control and dosimetry protocols specific for each technique [4-7]. However, so far, all the proposals researched showed differences among themselves, which puts under suspicion the overall effectiveness of its methods [8].For this computational/theoretical explorations, were used numerical solutions obtained by the Monte Carlo method, aiming to generate own computer data to illustrate the argument presented here.

It is hoped that this, can contribute significantly to the clarification of this research frontier in dosimetry and promote initiatives to collaborate with the worldwide broadcast, efforts to build new knowledge and techniques applicable to this context.

\subsection{Small Fields: What is it?}

The qualification of a particular field of photons as small or conventional is controversial because there is no consensus in the literature on a boundary that distinguishes them precisely [8]. The reason for this controversy is due to the effects arousing particular concern in small fields are also found in conventional fields, however, in the conventional field, these effects are manifested more subtle or imperceptible and therefore, can be considered negligible [9].

Therefore, what is observed for continuous decreases the size of the fields, is a gradual increase of disturbance in dosimetric behavior. When the dimensions of the equivalent fields approach $4 \times 4 \mathrm{~cm}^{2}$, these disturbances become significant enough to interfere deleterious manner in delivering the dose to the target volume.

The sources of such interference are assigned to some missing factors that are considered standards in the dosimetry of conventional fields, such as the loss of charged-particle equilibrium; blocking part of the field source collimation by the system and the fact of the detector dimensions are comparable to the size of the field.

These new physical conditions hinder the use of traditional dosimetric methods such as the use of cavity theory, either with its traditional formalism, or with the more modern formalism [9-13]. Indra (2008) has presented a clear demonstration of this issue. In his paper, the author presents an exploration of the differences in the responses of different commercially available dosimeters when they are used for dosimetry of conventional fields and small fields. The results presented indicate a high probability of significant errors in the delivered doses in medical exposures employing equivalent fields smaller than $4 \times 4 \mathrm{~cm}^{2}[9]$.

These differences also affect sizing the fields since due to the penumbra effects caused by the proximity of the field size and the source size, its geometric dimensions do not match the dosimetric dimensions [11].

In this work was carried out an investigation of the physical characteristics that hinder a more accurate dosimetry of non-standard fields in order to contribute to the effort to overcome the theoretical and practical obstacle mentioned. This is important, for maximizing the effectiveness of all medical exposures employing fields with these characteristics. 


\subsection{Materials and Methods}

\subsection{Code of Computer Simulation}

The data presented here, were obtained through computer simulations employing the Monte Carlo method to simulate the transport of ionizing radiation and the interaction of radiation with matter.

The simulations were performed using a modified version of egs chamber code, an implementation derived from EGSnrc radiation transport code in its latest version written in the language $C++[14]$.

The EGSnrc, although it can be used for any application involving ionizing radiation, has a specially focused vocation to the medical purposes, due to the large number of applications developed for this purpose, and ease of deployment and redeployment other applications for the same research area [14-16].

\subsection{The Accelerator Model}

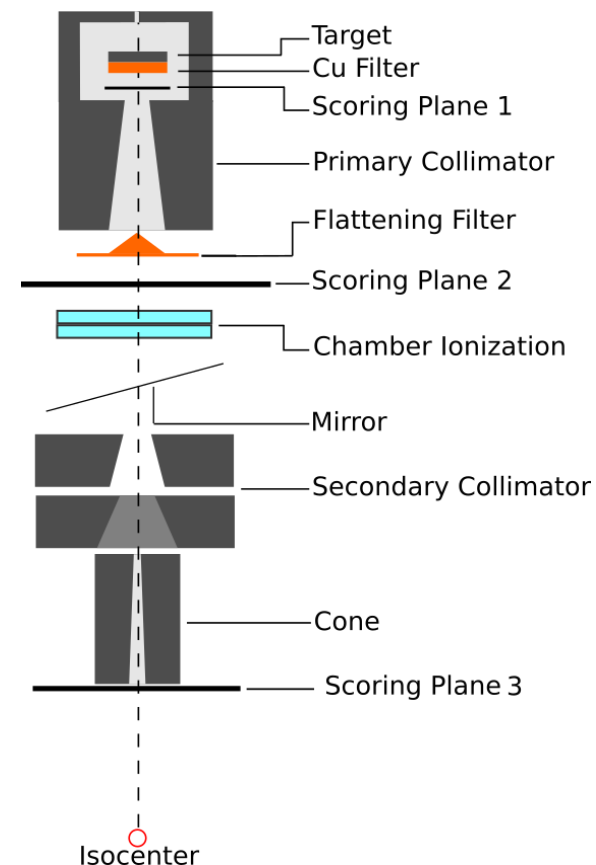

Figure 1: Sectional representation of the head model used for the simulation of the accelerator.

The linear accelerator used as a reference, was a Varian Clinac $2100 \mathrm{C}$, operating in a radiotherapy service in the city of Belo Horizonte, which produces non-standard beams by the obstruction of the main beam with small diameter cones made of lead and steel coated. It was modeled and simulated by the derived application BEAMnrc [15] using the method already employed by the authors in other works [17]. A cutaway view of components used for the model construction can be observed in Figure 1.

\subsection{Description of SRS Cones}

The cones in the model perform the function of a third Collimation System, which is responsible for sealing up the beam until usual dimensions for the SRS technique. Therefore, being they are one of the most important parts for the small field characterization.

Each cone, used in the clinical routine of radiotherapy, consists of a lead cylinder with a height of $120 \mathrm{~mm}$, surrounded by a steel skin of $5 \mathrm{~mm}$ thickness. The inside part of these cylinders has a conical hole with a solid angle that provides a light field equal to the nominal cone diameter in its isocenter.

In this study, 12 cones with nominal diameters between $9 \mathrm{~mm}$ and $42 \mathrm{~mm}$ were used. However, due to a matter of computational demand, dose side profiles and Collision Kerma values were calculated only for cones with $9,21,33$ and $42 \mathrm{~mm}$ nominal diameter.2.4 Computational Dosimetry

For the dosimetry, a cubic phantom model with a $30 \mathrm{~cm}$ edge was used. In this phantom was added a non-voxel based geometry of detectors specialists in obtaining results of higher precision in fields with low statistical particles, as is the case of small fields. This geometry uses modern algorithms that promote the improvement of cross sections (XCSE) and production phase space intermediate files (PSPP). Techniques that permit production of highly reliable results and reduce the computing time required for the simulations [18].

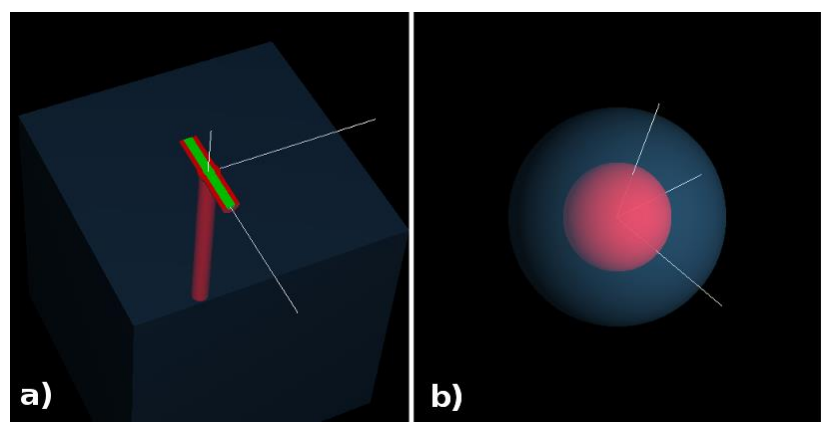

Figure 2: Detection geometry (a) Lateral and depth layout of the detectors, (b) specialized detectors used for dosimetry.

In Figure $2 \mathrm{a}$ can be seen geometry detection employed to obtain the data, volumes highlighted in red are those where happens the improvement of XCSE cross-section. IPSS was registered, at the outer limit of the green volume, and inside was positioned this specialized detectors, its geometry can be seen in Figure $2 b$. 


\subsection{Quantities Measures}

During the simulations were evaluated two quantities of interest for analysis, Depth Collision Kerma and the Depth Dose. Such quantities are fundamental to verify the discrepancy between the dose delivered to the target volume and one that is obtained by the use of conventional dosimetric formulation, valid for small radiation fields. These parameters also serve as an indication of how much the simulated fields coincide or not with the collision kerma in depth after the maximum dose point.

Figure 3 shows the behavior traditionally expected in conventional fields indirectly ionizing radiation, comprising the classic conditions of charged-particle equilibrium (CPE) and transient charged-particle equilibrium (TCPE).
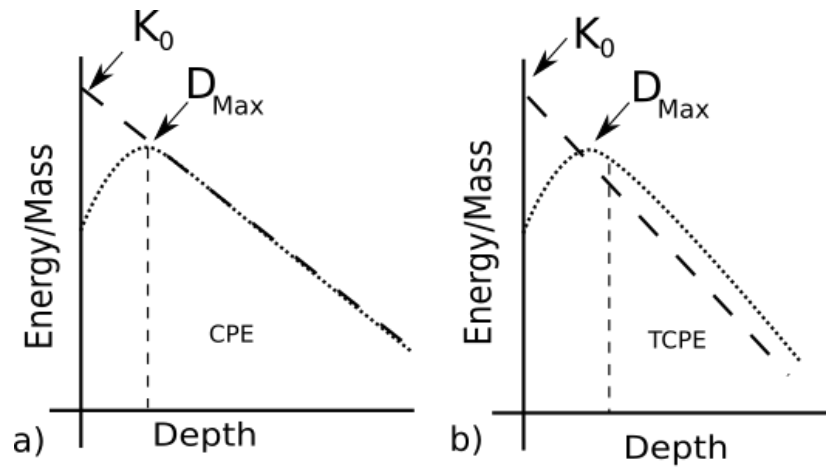

\section{Collision Kerma Dose}

Figure 3: Theoretical relationship between dose and the depth Collision Kerma in a low atomic number media, exposed to indirectly ionizing radiation field. (A) In condition of chargedparticle equilibrium, $(B)$ in condition of transient charged-particle equilibrium (Attix, 2004 - modified).

The charged-particle equilibrium refers to the more classical physical condition of dosimetry that establishes the numerical equivalence of the dose deposited in the media (D) and the collision kerma (Kc), which can mathematically be written as equation 1.

$$
\left(D=K_{C}\right)_{C P E}
$$

The second condition, similar to the first requires the introduction of an additional factor that modifies the position of Collision Kerma curve in relation to the dose curve of the form given by equation 2 .

$$
\left(D=K_{C}+b\right)_{T C P E}
$$

According to Roesch (1958) [19] the coefficient b added to the equation 2 can be described as a function of the common slope between the curves of
Dose and Collision Kerma and the mean distance of path of the secondary particles in the direction of primary beam. With the application of this concept, equation 2 is modified assuming the form shown in equation 3.

$$
\left[D=K_{C}\left(1+\mu^{\prime} \bar{x}\right)\right]_{T C P E}
$$

In any case, the ratio between the dose and Collision Kerma may be associated with a constant $\left(1+\mu^{\prime} \bar{x}\right)$, which may be unitary or not according to the values assumed by $\left(\mu^{\prime} \bar{x}\right)$. This property was used to check the commitment in the establishment of charged-particle equilibrium modes in small fields. The Collision Kerma values were transcribed in a trend line through a linear regression to the data generated in order to obtain a global behavior of this magnitude.

An estimation of discrepancy between the Collision Kerma and Dose Curve can be established through the Average Absolute Discrepancy (AAD). In this work, AAD was defined as the absolute average of the discrepancy between the Collision Kerma and the Dose at points with depth equal or greater than to the maximum dose point. The mathematical method to obtain this value can be found in equation 4.

$$
A A D=\left(\frac{1}{N} \sum_{i}^{N} \frac{\left|K_{C} i-D i\right|}{D i}\right) \cdot 100 \%
$$

At the same time, the Uncertainty $(\sigma)$ was estimated as the average standard deviation of the values assumed by the absolute percentage discrepancy, as can be seen in equation 5 .

$$
\sigma=\frac{\frac{1}{N-1} \sum_{i}^{N}\left(\frac{\left|K_{C} i-D i\right|}{D i} \cdot 100 \%-A A D\right)^{2}}{\sqrt{N}}
$$

The lateral doses in the phantom surface were also measured and, with these data, it was possible to demonstrate the incompatibility between the dosimetric dimensions of small fields with nominal geometrical sizes. 


\subsection{Results and discussions}

\subsection{Field Dimensions}

Figure 4 shows the lateral normalized dose profile of four different circular fields with diameter of 9,21 and $33 \mathrm{~mm}$ obtained by SRS cones and a square field of $50 \times 50 \mathrm{~mm}^{2}$. Can be clearly seen in the characteristic curve of the field $50 \times 50 \mathrm{~mm}^{2}$, that the field width at half maximum of the maximum intensity (FWHM), focuses very well on the points $2.5 \mathrm{~cm}$ and presumably on its symmetrical point. However, the incidence of FWHM exactly on the geometrical dimensions of the beam does not occur in smaller fields indicating the incompatibility already

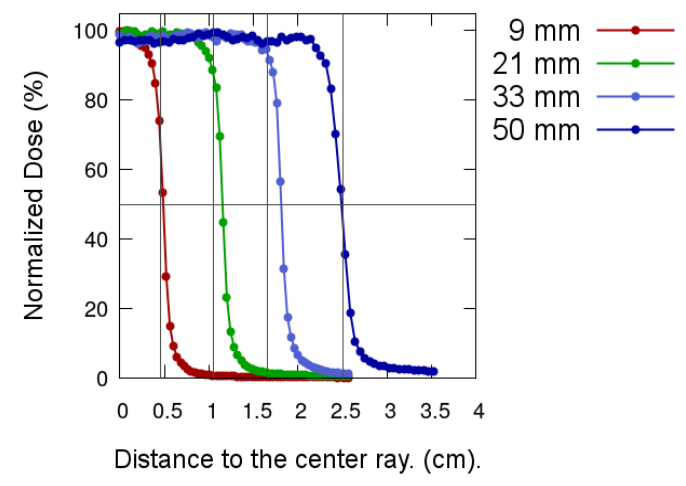

mentioned.

Figure 4: Side Profile Dose normalized to fields 9, 21, 33 and 50 $\mathrm{mm}$ lateral opening. The horizontal line marks the height equivalent to $50 \%$ and vertical geometric dimensions expected for the field.

Could initially be assumed that an increase of these discrepancies occurs simultaneously with the decreasing size of the simulated field, however, this was not a valid assumption, as can be seen in Figure 5.

What was found was a significant increase of this magnitude to a certain level slightly lower than the $10 \%$, which remained approximately constant for fields with circular areas values between 2 and 12 $\mathrm{cm}^{2}$ approximately. For areas outside this range, lower values of absolute differences were observed.

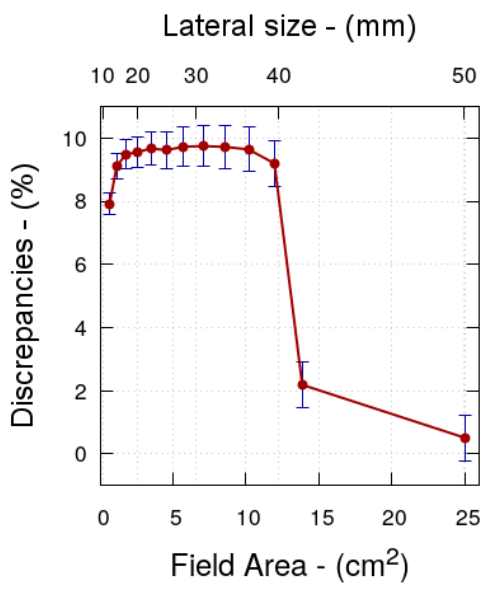

Figure 5: Absolute Discrepancies between nominal geometric dimensions of the field and the FWHM.

\subsection{Charged-Particle Equilibrium Analysis}

All Collision Kerma values, had approximately linear behavior, the dots have an average $3 \%$ of dispersion by using a straight line obtained by linear regression as reference. Line was used to represent the Collision Kerma in the simulated fields.

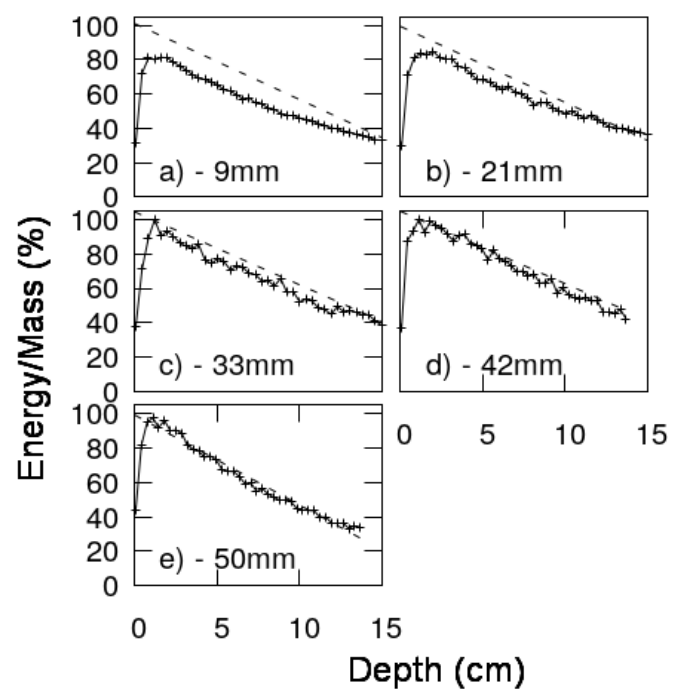

Figure 6: Depth dose (solid line and points) and depth Collision Kerma (dotted line).

Figure 6 displays charts containing the curves obtained by linear regression of the Collision Kerma (dotted line) and by the Percentage Depth Dose. These values were obtained from the circular fields with diameter of $9,21,33$ and $42 \mathrm{~mm}$ and a square field with sides of $50 \mathrm{~mm}$. By means of the charts, it can be seen that these doses had the characteristic behavior of classical depth-dose curves percentage. However, the relationship between dose and Collision Kerma showed deviant behavior that expected for establishing conditions CPE and TCPE 
in the fields of diameter less than $21 \mathrm{~mm}$. In these fields, besides the non-coincidence of the Depth Collision Kerma and Percentage Depth Dose curves a disagreement of its angular coefficients was observed too. For the nominal field diameter equal to $33 \mathrm{~mm}$, there is a good approximation of the slope coefficients, but Dose and Collision Kerma still have discrepancies higher than the uncertainty of the measurements. Indicating what appears to be the behavior of a TCPE condition. The fields of $42 \mathrm{~mm}$ and $50 \times 50 \mathrm{~mm}^{2}$, technically there was achieving of CPE conditions.

More explicitly, Table 1 shows the Average Absolute Discrepancy between Kerma collision and dose for the curves shown in Figure 6

Table1: Average absolute discrepancy between Kerma collision and dose at depths below the maximum dose point.

\begin{tabular}{cccccc}
\hline Average & $\mathbf{9} \mathbf{m m}$ & $\mathbf{2 1} \mathbf{m m}$ & $\mathbf{3 3} \mathbf{m m}$ & $\mathbf{4 2} \mathbf{m m}$ & $\mathbf{5 0 \times 5 0} \mathbf{m m}^{2}$ \\
& $14 \%$ & $8 \%$ & $5 \%$ & $<2 \%$ & $<1 \%$ \\
& $\pm 3 \%$ & $\pm 2 \%$ & $\pm 1 \%$ & & \\
\hline
\end{tabular}

\subsection{Relevant Methodological Aspects}

The Monte Carlo simulations, regardless of its applicability, resulting in data associated with a nonabsolute reliability, that is, there are always uncertainties associated with each of the calculated data. In the simulations of this study were determined as permissible values, $2 \%$ uncertainty to the side doses shown in Figure 4 and propagated to Figure 5 , from $1 \%$ to the amount of uncertainty in depth and $4 \%$ in the collision kerma uncertainties. Therefore, one should consider these values as those representatives of the data reliability presented.

Figure 5 shows a decrease in the absolute discrepancy between the geometrical and dosimetric sizes of fields with diameters less than $15 \mathrm{~mm}$. The causes of this reduction has not yet been identified by authors, and may be associated with the most severe dosimetric compromises due to the range of secondary particles are in some cases, larger than the dimensions of the field, in contrast to the small dimensions of the detector used. Extrapolation of this behavior for smaller fields should not be considered a valid conclusion to such a phenomenon before further investigation about him are realized. It should be emphasized that in recent literature, have not found any solid statements about this characteristic increased precision of the field.

Another methodological issue that deserves consideration refers to the simultaneous use of data circular and square fields. The high computational demand for the realization of the simulations and the unavailability of a computational model commissioned of other collimation forms for small fields, prevented this weakness was avoided. Therefore, should be treated with some caution the effective continuity of dosimetric behavior between square and circular fields, considering the possibility of dosimetric fluctuations when square and circular equivalent fields are used. Work in this respect are suggested for bulking data about the reliability of the Monte Carlo method and radiation transport codes for the simulation of small fields.

Linear regression applied to the representation of the Collision Kerma is a factor that introduces additional errors in our data, despite this low dispersion of the points in Collision Kerma curve, made it possible to obtain this line maintaining at acceptable levels accumulated errors, as can be seen in the data in Table 1.

\subsection{Conclusion}

The data showed an unexpected behavior in relation to the accuracy of dimensions of small fields. It was expected that data would confirm a gradual decrease in the accuracy of the field when the magnitude was measured by the absolute discrepancy between nominal size of the field at the isocenter and the dose FWHM.

However, the data demonstrate an increase in accuracy in the very small fields. Furthermore, a constant level of precision was observed in the size of the fields that extended the beam diameter from $15 \mathrm{~mm}$ to $36 \mathrm{~mm}$.

The verification of establishment or nonestablishment of CPE and TCPE conditions proved to be quite satisfactory, although an additional uncertainty occurred in Collision Kerma data. It was found that in extreme conditions, such as a circular field diameter $9 \mathrm{~mm}$, occur on average 14\% dosimetric errors, reaching up to $20 \%$. At the same time, the largest fields data, showed that the CPE reestablishes very quickly to larger fields, being fully achieved in square fields of $50 \times 50 \mathrm{~mm}^{2}$.

\section{Acknowledgements}

The authors thank the Radiotherapy Service of the Santa Casa de Belo Horizonte, by the availability of data that allowed the modeling of the accelerator and cones used in this work.

The authors also thank Gustavo Condé Almeida Dias for his precious comments on the English manuscript. 


\section{References}

1. Sean MM, Douglas SW, Bonnie $\mathrm{H}$ et al. Hypofractionated Stereotactic Body Radiotherapy in Low-Risk Prostate Adenocarcinoma, Nuclear Instruments and Methods in Physics Research A . 2012, 118, 3681-90.

2. Yasushi N, Yoshiharu N, Tetsuya A, et al. Clinical Outcomes of 3D Conformal Hypofractionated Single High-Dose Radiotherapy for one or Two Lung Tumors Using A Stereotactic Body Frame, Radiation Oncology Biology and Physics, 2002, 52, 1041-6.

3. Daniel AL, Jean MM, James FD, et al. Dosimetry tools and techniques for IMRT, 2011, Medical Physics, 38, 1313-38.

4. Sonja D, Carlo C, Cynthia FC, et al. Report of AAPM TG 135: Quality assurance for robotic radiosurgery, Medical Physics, 2011, 38, 2914-36.

5. Michael CS, Frank JB, David AL, et al. Stereotactic Radiosurgery: Report of Task Group 42 - Radiation Therapy, Comittee, American Association of Physicists in Medicine, 2011.

6. Christos A, Evaggelos P. Performance Evaluation of a CyberKnif Robotic Stereotactic RadioSurgery System, Physics in Medicine and Biology, 2008, 53, 4697-718.

7. Alfonso R, Andreo P, Huq MS, et al. A new formalism for reference dosimetry of small and nonstandard fields, Medical Physics, 2008, 35, 5179-186.

8. Indra JD, George XD, Anders A. Small Fields: Nonequilibrium Radiation Dosimetry,

Medical Physics, 2008, 35, 206-15.

9. Philip M, Alan N, Jean-Claude R. Handbook of Radiotherapy Physics: Theory and Practice, Boca Raton: Taylor \& Francis Group; 2007.

10. C-M CM, Alan N. Bragg Gray theory and ion chamber dosimetry for photon beams, 1991, Physics in Medicine and Biology, 36, 413-28.

11. Attix FH, De La Vergne L, Ritz VH, Cavity ionisation as a function of wall material, 1958, J. Res. NBS, 60, 235.

12. Attix $\mathrm{FH}$, The partition of kerma to account for bremsstrahlung Health Phys, 1979, 36, 347-54.

13. Stanley HB, David JS, Steven JG, et al. Stereotactic Radiosurgery and Stereotactic Body Radiation Therapy, Boca Raton: Taylor \& Francis Group; 2015.

14. Kawrakow I, Mainegra-Hing E, Rogers DWO, et al. The EGSnrc Code System: Monte Carlo Simulation of Electron and Photon Transport, Ottawa: National Research Council Canada, 2016.

15. Rogers DWO, Walters B, Kawrakow I, BEAMnrc Users Manual, Ottawa: National Research Council Canada, 2016.

16. Walters B, Kawrakow I, Rogers DWO. DOSXYZnrc Users Manual, Ottawa: National Research Council Canada, 2016.

17. Reginaldo GLJr, Arno HO, Rômulo VS, et al. Modeling and Commissioning of a Clinac $600 \mathrm{CD}$ by Monte Carlo method using the BEAMnrc and DOSXYZnrc codes, 2015, INAC, São Paulo.

18. Reginaldo GLJr, Arnaldo PM, Rômulo VS, et al. Desenvolvimento de Geometria Especialista em Dosimetria Numérica de Pequenos Campos por Método de Monte Carlo, Utilizando o Código EGSNRC, 2016, III SENCIR, Belo Horizonte.
19. Roesch WC, Dose for nonelectronic equilibrieum conditions, 1958, Radiation Research, 9, 399-410. 